\title{
Faktor-Faktor yang Mempengaruhi Produksi Padi Sawah di Kecamatan Biboki Moenleu Kabupaten Timor Tengah Utara Provinsi Nusa Tenggara Timur
}

\author{
Yosefina Marice Fallo ${ }^{a}$ I Made Narka Tenaya ${ }^{b}$ dan I Dewa Gede Agung ${ }^{b}$ \\ ${ }^{a}$ Fakultas Pertanian, Universitas Timor, Kefamenanu, TTU - NTT, Indonesia. \\ ${ }^{b}$ Fakultas Pertanian Universitas Udayana, Denpasar - Bali, Indonesia.
}

\section{Article Info}

Article history:

Received 20 September 2018

Received in revised form 9 Oktober 2018

Accepted 27 Oktober 2018

\section{DOI:}

https://doi.org/10.32938/ag.v3i4.483

\section{Keywords:}

Padi Sawah

Produksi

Biboki Moenleu

\section{Abstrak}

Usahatani padi sawah yang merupakan sumber utama pendapatan petani di Kecamatan Biboki Moenleu yang masih bersifat semi komersial, produksi padi sawah yang dihasilkan tidak semuanya dipasarkan untuk memenuhi kebutuhan hidup rumah tangga tetapi sebagian untuk di konsumsi. Upaya peningkatan produksi padi sawah dipengaruhi oleh berbagai faktor di antaranya faktor produksi, lingkungan, serta faktor sosial ekonomi. Pada kenyataannya petani belum sepenuhnya memanfaatkan lahan secara baik, sehingga masih tersisa lahan tidur padahal air bukanlah menjadi kendala. Dalam setahun petani dapat melakukan dua kali penanaman. Penelitian dilakukan di Kecamatan Biboki Moenleu, Desa Oepuah, Oepuah Utara, dan Oepuah Selatan. Obyek penelitian adalah petani padi sawah sebanyak 200 responden. Tujuan penelitian untuk mengetahui pengaruh secara simultan antara faktor-faktor produksi terhadap produksi padi sawah, untuk mengetahui dan menggambarkan pengaruh secara parsial antara faktor-faktor produksi terhadap produksi padi sawah. Hasi penelitian menunjukkan bahwa secara simultan menunjukkan bahwa secara bersama-sama faktor produksi utama satu dan faktor produks utama dua yaitu: luas lahan, bibit, penggunaan tenaga kerja, umur, dan pendidikan sedangkan, faktor produksi pendukung satu, dan fakto produksi pendukung dua yaitu: yaitu penggunaan pupuk, obat-obatan, dan sistem pengelolaan yang berpengaruh terhadap produksi padi sawah adalah sangat nyata. Faktor produksi utama satu yakni luas lahan, bibit, penggunaan tenaga kerja, umur, dan pendidikan sedangkan, faktor produksi pendukung satu yaitu penggunaan pupuk, obat-obatan, dan sistem pengelolaan yang berpengaruh nyata terhadap produksi padi sawah. Sedangkan, yang lainnya tidak berpengaruh.

\section{Pendahuluan}

Sumber daya lahan di Kabupaten Timor Tengah Utara (TTU) Provinsi Nusa Tenggara Timur (NTT) masih sangat berpotensi untuk pengembangan pertanian. Menurut laporan BPS Kab. TTU, (2008), Kabupaten TTU memiliki luas lahan pertanian yang cukup besar yaitu 56.600 ha dari luas daratan sebesar 266.970 ha, luas lahan yang telah dimanfaatkan untuk usaha pertanian lahan kering sebesar 48.412 ha sedangkan luas lahan sawah adalah 8.188 ha yang tersebar 24 Kecamatan. Kecamatan Biboki Moenleu merupakan salah satu daerah pertanian yang mengembangkan usaha padi sawah di Kabupaten TTU dari luasan tersebut lahan sawah mempunyai peranan yang strategis dalam penyediaan air irigasi.

Upaya peningkatan padi sawah dipengaruhi oleh berbagai faktor antara lain faktor produksi (lahan, bibit, tenaga kerja, modal, dan pengelolaan), lingkungan, serta faktor sosial ekonomi. Beberapa penelitian terdahulu telah memberikan gambaran tentang faktor-faktor yang berpengaruh terhadap produksi padi. Penelitian Triyanto, (2006) memberikan gambaran bahwa variabel luas lahan, tenaga kerja, benih dan pompa air, memberikan pengaruh positif yang signifikan sedangkan variabel pupuk mempunyai hubungan yang positif tetapi tidak signifikan dalam mempengaruhi produksi padi di Jawa Tengah. Selanjutnya hasi penelitian Desky, (2008) menunjukkan bahwa secara parsial hanya variabel luas lahan, dan jumlah pekerja yang berpengaruh positif dan signifikan terhadap produksi padi, sementara variabel pestisida berpengaruh signifikan dengan korelasinya negatif terhadap produksi padi di Kabupaten Aceh Tenggara.

Pada kenyataannya petani di Kecamatan Biboki Moenleu belum sepenuhnya memanfaatkan lahan secara baik, sehingga masih tersisa lahan tidur padahal ai bukanlah menjadi kendala. Dalam setahun petani dapat melakukan dua kal penanaman. Di samping itu, yang digunakan hanya pupuk Urea, hal in disebabkan kurangnya pengetahuan petani tentang manfaat dari pemupukan itu sendiri. Dampak dari kurangnya pengetahuan petani, membuat kurangnya perincian modal untuk usahatani sehingga pembelian input seperti pestisida kurang digunakan. Selain itu pemanfaatan tenaga kerja pun tidak semaksimal mungkin sebagai akibat dari keterbatasan modal. Keterbatasan-keterbatasan yang ada mengakibatkan produksi yang diperoleh belum optimal. Dengan demikian, maka diadakan penelitian dengan judul faktor-faktor yang mempengaruhi produksi padi sawah di Kecamatan Biboki Moenleu, Kabupaten TTU, Provinsi NTT.

Tujuan dari penelitian ini adalah 1). Untuk mengetahui pengaruh secara simultan antara faktor-faktor produksi (luas lahan, bibit, tenaga kerja, pupuk, obat-obatan, dan pengelolaan) terhadap produksi padi sawah, 2). Untuk mengetahui dan menggambarkan pengaruh secara parsial antara faktor-faktor produksi (luas lahan, bibit, tenaga kerja, pupuk, obat-obatan, dan pengelolaan) terhadap produksi padi sawah di Kecamatan Biboki Moenleu, Kabupaten TTU, Provinsi NTT

\section{Metode}

Penelitian dilakukan di Kecamatan Biboki Moenleu, Kabupaten TTU dengan dasar pertimbangan bahwa Kecamatan Biboki Moenleu memiliki luas lahan sawah dengan sistem irigasi yang terluas dari 24 Kecamatan di Kabupaten TTU, Provinsi NTT. Objek penelitian adalah petani padi sawah. Populasi dalam penelitian ini adalah petani padi sawah di tiga Desa yaitu Desa Oepuah, Desa Oepuah Utara, dan Desa Oepuah Selatan yang diambil dengan dasa pertimbangan bahwa ketiga desa tersebut memiliki luas lahan sawah tertinggi dari tujuh desa yang ada di Kecamatan Biboki Moenleu.

Penentuan sampel menggunakan proporsional, dari jumlah Kepala Keluarga Tani (KKT) dengan dasar pertimbangan bahwa jumlah kepala keluarga taninya paling banyak yaitu Desa Oepuah sebanyak 80 responden, Desa Oepuah utara sebanyak 50 responden, Desa Oepuah Selatan sebanyak 70 responden, sehingga total responden adalah sebanyak 200 orang petani. Untuk pengambilan responden menggunakan metode acak sederhana sesuai pedoman Siagian \& Sugiarto, (2006).

Pengumpulan data dilakukan dengan metode wawancara, observasi, dan studi dokumentasi. Defenisi operasional variabel yang digunakan dalam penelitian ini adalah:

a. Lahan merupakan luas lahan yang digarap oleh petani di Kecamatan Moenleu baik sebagai petani pemilik mampu petani penyakap.

b. Bibit merupakan bibit yang dibuat sendiri oleh petani dari padi sawah yang unggul.

c. Umur dihitung dalam tahun dengan pembulatan ke bawah, atau umu menurut ulang tahun terakhir.

d. Pendidikan dalam hal ini adalah pendidikan tertinggi yang ditamatkan merupakan jenjang pendidikan yang telah diselesaikan pada saat pencacahan.

e. Tenaga kerja adalah tenaga kerja dalam keluarga dan tenaga kerja luar keluarga.

f. Tenaga kerja dalam keluarga adalah anggota keluarga yang tinggal seatap, yang menyumbangkan tenaganya dalam kegiatan usahatani, (umumnya tidak diperhitungkan), tetapi dalam penelitian ini tenaga dalam keluarga tetap diperhitungkan yaitu: pria, wanita, dan anak-anak.

g. Tenaga kerja luar keluarga adalah tenaga kerja yang diperoleh dengan cara diupah, dan sambatan (saling tolong menolong antar petani), yaitu: pria, wanita, dan mesin.

h. Pupuk yang digunakan adalah pupuk yaitu Urea, TSP, KCL, dan pupuk organik

i. Obat-obatan adalah zat yang digunakan untuk pencegahan hama dan penyakit mulai dari penanaman, pemeliharaan sampai panen yaitu: Akodan, Kiltop, Icon, Bassa, Alamin, dan Furadan

j. Pengelolaan adalah kemampuan petani menentukan, mengorganisir, dan mengkoordinasi faktor-faktor produksi yaitu kegiatan-kegiatan pemeliharaan proses produksi.

k. Faktor produksi utama merupakan faktor produksi yang sangat penting dan harus ada untuk menghasilkan padi sawah yaitu tanah, bibit, dan tenaga kerja

1. Faktor produksi pendukung merupakan faktor produksi yang digunakan untuk meningkatkan produksi baik mutu dan jumlah yaitu pupuk, obat-obatan, dan pengelolaan

m. Variabel laten adalah variabel yang dibentuk oleh beberapa variabel pengamatan.

n. Variabel konstruk adalah variabel yang dibentuk oleh beberapa variabel pengamatan

o. Variabel dimensi adalah variabel yang diamati.

p. Faktor primer adalah beberapa variabel yang dibentuk seperti faktor tenaga kerja dalam keluarga yang dibentuk oleh beberapa variabel pengamatan (pria, wanita, dan anak-anak), sedangkan faktor tenaga kerja luar keluarga dibentuk oleh beberapa variabel pengamatan (pria, wanita, dan mesin), sedangkan fakto pengelolaan dibentuk oleh beberapa variabel pengamatan (Penanaman, penyiangan, pengairan, dan pemupukan)

q. Faktor sekunder adalah variabel yang dibentuk dari beberapa faktor primer r. Faktor tersier adalah variabel yang dibentuk dari beberapa faktor sekunder. s. Produksi padi sawah adalah hasil kali antara produk padi sawah dengan harga gabah yang berlaku di petani. Dengan kata lain produksi adalah barang yang telah siap untuk dipasarkan dan barang yang masih dalam proses (setengah jadi/gabah), semua barang hasil produksi harus dinilai walaupun belum dijual, sudah dijual (tunai maupun kredit), dikonsumsi sendiri, dan dihadiahkan. 
Jenis data yang digunakan dalam penelitian ini adalah data kuantitatif dan data kualitatif. Sugiyono, (2006) mengemukakan bahwa data kuantitatif merupakan data atau berwujud kuantitas yang dapat dihitung sebagai berikut: produksi, biaya tenaga kerja, biaya bibit, biaya pupuk, dan biaya obat-obatan. Sedangkan, data kualitatif yang dibutuhkan dalam penelitian ini adalah: identitas responden yakni umur, tingkat pendidikan, luas lahan dan sistem pengelolaan.

Data primer yaitu data yang diperoleh dari hasil wawancara dengan menggunakan daftar pertanyaan, dalam hal ini data yang diperoleh dari pertani padi sawah. Data yang diambil atau dikumpulkan adalah data satu kali musim tanam tahun 2009. Data sekunder yaitu data yang diperoleh secara tidak langsung atau pihak kedua, yaitu instansi terkait.

Analisis data dalam penelitian ini menggunakan analisis SEM. Analisis faktor dan analisis regresi berganda, sedangkan path diagram tersebut akan memudahkan peneliti melihat hubungan-hubungan kausalitas yang ingin diuji dan selanjutnya bahasa program akan mengonversikan gambar menjadi persamaan. Dalam pemodelan ini peneliti bekerja dengan faktor produksi utama, faktor produksi pendukung, dan faktor tenaga kerja. Hubungan antar konstruk akan dinyatakan dengan tanda panah, dimana anak panah yang lurus menunjukkan hubungan kausal yang langsung antara satu konstruk dengan konstruk lain. Sedangkan, garis lengkung dengan anak panah pada setiap ujungnya menyatakan korelasi antar konstruk (Ghozali, 2004). Untuk lebih jelas dapat dilihat pada diagram alur pada Gambar 1

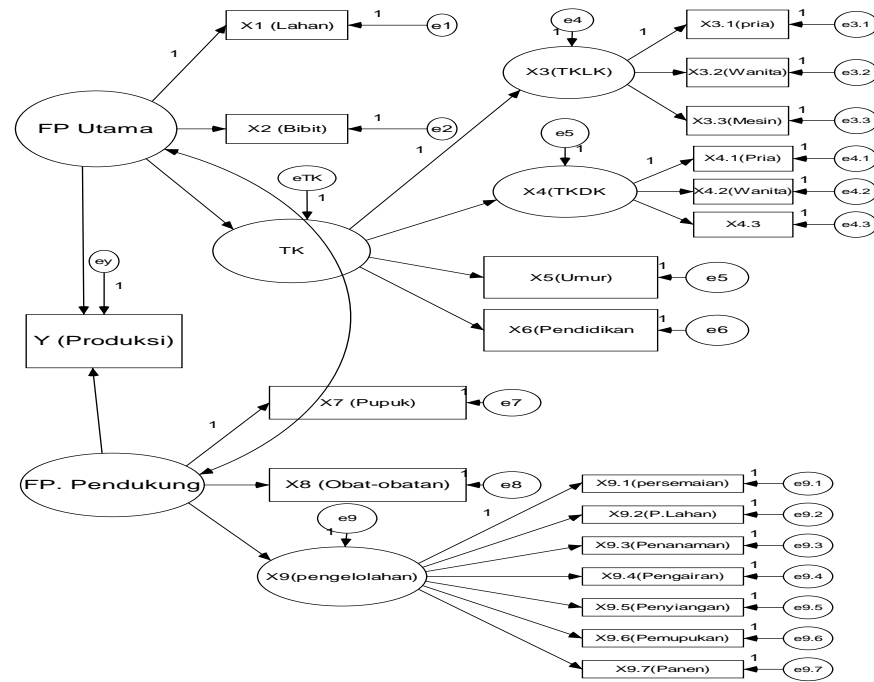

Gambar 1. Path Diagram Faktor-faktor yang Mempengaruhi Produksi Padi Sawah

\subsection{Analisis Faktor}

Dalam penelitian ini terdapat enam variabel laten yang akan difaktorkan untuk menemukan satu variabel nyata yaitu: (1) tenaga kerja luar keluarga $\left(\mathrm{X}_{3}\right)$, (2) tenaga kerja dalam keluarga $\left(\mathrm{X}_{4}\right)$, (3) faktor tenaga kerja (TK), (4) pengelolaan $\left(\mathrm{X}_{9}\right)$, (5) faktor produksi utama (FPU), dan faktor produksi pendukung (FPP). Dapat diketahui bahwa variabel tenaga kerja luar keluarga diringkas dari tenaga kerja pria $\left(\mathrm{X}_{3.1}\right)$, wanita $\left(\mathrm{X}_{3.2}\right)$, dan mesin $\left(\mathrm{X}_{3.3}\right)$, tenaga kerja dalam keluarga diringkas dari tenaga kerja pria $\left(\mathrm{X}_{4.1}\right)$, wanita $\left(\mathrm{X}_{4.2}\right)$, dan anakanak $\left(\mathrm{X}_{4.3}\right)$, sedangkan variabel pengelolaan diringkas dari penanaman $\left(\mathrm{X}_{9.3}\right)$, pengairan $\left(\mathrm{X}_{9.4}\right)$, penyiangan $\left(\mathrm{X}_{9.5}\right)$, dan pemupukan $\left(\mathrm{X}_{9.6}\right)$.

Suatu data layak dan tidaknya untuk dilakukan analisis faktor, secara statistik menggunakan uji Kaiser-Meyer-Olkin (KMO) measure of adequacy dan Barlett Test of spericity. KMO yang digunakan untuk mengukur kecukupan sampel dengan cara membandingkan besarnya koefisien korelasi yang diamati dengan koefisien parsialnya. Jika harga KMO > 0,05 maka dapat diterima atau analisis faktor layak dilakukan. Barlett Test merupakan test statistik untuk menguji apakah betul variabel-variabel bebas yang dilibatkan berkorelasi atau tidak. kriteria uji dengan melihat p-value (signifikasi): terima Ho jika sig. $<0,05$ atau tolak Ho $<0,05$ dimana $\mathrm{Ho}=$ tidak ada korelasi antar variabel bebas dan $\mathrm{H} 1$ $=$ ada korelasi antar variabel bebas.

\subsection{Analisis Regresi Berganda}

Tujuan dilakukan analisis regresi berganda adalah untuk mengukur seberapa besar hubungan dua variabel atau lebih yang dinyatakan dengan bentuk hubungan dua fungsi. Untuk menentukan bentuk hubungan (regresi) maka diperlukan pemisahan yang tegas antara variabel eksogenous dan variabel endogenous. Dengan demikian, maka regresi merupakan suatu bentuk fungsi tertentu antara variabel tak bebas $(\mathrm{Y})$ dengan variabel bebas $(\mathrm{X})$ yang selanjutnya dapat dinyatakan bahwa regresi adalah sebagai $Y=F(X)$ (Tenaya, 2006).

Setelah diketahui faktor yang terbentuk dari analisis faktor maka selanjutnya kita melalukan analisis regresi faktor. Adapun formulasi persamaan regresi faktor menurut Tenaya, (2006) adalah $\hat{\mathrm{Y}}=\beta \mathrm{o}+\beta_{1} \mathrm{Fak}_{1}+\beta_{2} \mathrm{Fak}_{2}+\ldots \ldots+\beta_{\mathrm{i}} \mathrm{Fak}_{\mathrm{i}}$ dimana:

$$
\begin{array}{ll}
\hat{\mathrm{Y}} & =\text { Produksi padi sawah } \\
\mathrm{Fak}_{\mathrm{i}} & =\text { Faktor yang terbentuk }
\end{array}
$$
$\mathrm{Fak}_{1}=$ Faktor produksi utama 1
$\mathrm{Fak}_{2}=$ Faktor produksi utama 2
$\mathrm{Fak}_{3}=$ Faktor produksi pendukung 1
$\mathrm{Fak}_{4}=$ Faktor produksi pendukung 2
Bo $=$ Contant
$\beta \mathrm{i}=$ Koefisien regresi faktor untuk mengukur besarnya perubahan nilai Y jika Fak berubah

\section{Hasil dan Pembahasan}

\subsection{Analisis Faktor}

Analisis faktor variabel eksogen atau variabel bebasnya terdiri atas faktor produksi utama (FTU) dan faktor produksi pendukung (FPP). Hasil analisis untuk pembentukan faktor FPU dan FPP adalah seperti pada Tabel 1.

Tabel 1. Hasil Analisis Faktor, Nilai KMO, Chi-Square, dan Peluang (Sig)

\begin{tabular}{lcrrr}
\multicolumn{1}{c}{ Variabel/Faktor } & $\begin{array}{c}\text { Nilai } \\
\text { KMO }\end{array}$ & $\begin{array}{c}\% \\
\text { Varians } \\
\text { Total }\end{array}$ & $\begin{array}{c}\text { Pendekatan } \\
\text { Nilai Chi- } \\
\text { Square }\end{array}$ & Sig. \\
\hline $\begin{array}{l}\text { Tenaga Kerja Luar Keluarga } \\
\text { (FTLK) Tenaga Kerja Dalam }\end{array}$ & 0,734 & 85,67 & 445,430 & 0,000 \\
Keluarga (FTKDK) & & & & \\
Tenaga Kerja (FTK) & 0,510 & 49,27 & 41,272 & 0,000 \\
Pengelolaan (FP) & 0,500 & 49,27 & 57,57 & 0,035 \\
Produksi Utama (FPU) & 0,510 & 57,320 & 9,005 & 0,173 \\
Produksi Pendukung(FPP) & 0,684 & 89,795 & 452,370 & 0,000 \\
\hline
\end{tabular}

\subsection{Analisis Regresi Berganda}

Dalam analisis regresi linier berganda terhadap variabel (produksi padi sawah) atas variabel bebas faktor produksi utama (FPU) dan faktor produksi pendukung (FPP) dinyatakan dengan persamaan regresi linier berganda yakni Y $=\mathrm{bo}+\mathrm{b}_{1} \mathrm{FPU}+\mathrm{b}_{2} \mathrm{FPP}+\mathrm{e}$. Selanjutnya, analisis regresi yang digunakan dalam pengolahan data adalah: 1) Analisis regresi atau korelasi linier sederhana (linier regression/ correlation analysis), untuk melihat pengaruh individu variabel eksogen terhadap variabel endogen; dan 2) Analisis regresi linier berganda (multiple linier regression analysis), untuk melihat pengaruh secara simultan dan secara parsial variabel eksogen terhadap variabel endogenous,

a. Analisis Regresi atau Korelasi Linier Sederhana

Hasil analisis regresi atau korelasi linier sederhana antara faktor produksi utama (FPU) dan faktor produksi pendukung disajikan pada Tabel 2.

Tabel 2. Hasil Analisis Regresi /Korelasi Linier Sederhana

\begin{tabular}{lccccc}
\hline Pearson Correlation & FPU1 & FPU2 & FPP1 & FPP2 & Produksi \\
\hline FPU1 & 1 & 0,000 & $0,835^{* *}$ & $-0,154^{*}$ & $0,857^{* *}$ \\
FPU2 & & 1 & $-0,034$ & $-0,203^{* *}$ & $-0,007$ \\
FPP1 & & & 1 & 0,000 & $0,651^{* *}$ \\
FPP2 & & & & 1 & $-0,119$ \\
\hline
\end{tabular}

Dari Tabel 2. ternyata bahwa dua faktor yang berpengaruh sangat nyata terhadap produksi padi sawah (Y), yaitu faktor produksi utama satu (FPU1) sebesar $0,857(* *)$ dan faktor produksi pendukung satu (FPP1) sebesar 0,561(**). b. Analisis Regresi Linier Berganda

Hasil analisis regresi linier berganda antara faktor produksi utama (FPU) dan faktor produksi pendukung disajikan pada Tabel 3. dan Tabel 4. Pengaruh faktor produksi utama satu, faktor produksi utama dua, faktor produksi pendukung satu, dan faktor produksi pendukung dua terhadap produksi padi sawah adalah sangat nyata dengan nilai $F$ hitung sebesar 146,220 dan peluang $=0,000$. Dengan besarnya koefisien determinan $\left(\mathrm{R}^{2}\right)=0,750$, artinya besarnya pengaruh nilai faktor produksi utama satu, faktor produksi utama dua, faktor produksi pendukung satu, dan faktor produksi pendukung dua terhadap produksi padi sawah sebesar $75 \%$ sedangkan sisanya $25 \%$ dipengaruhi oleh faktor lain di luar model. Dapat saya asumsikan bahwa hasil penelitian sesuai dengan teori menurut Sutrisno \& Ananda, (2009) secara simultan faktor-faktor luas lahan garapan, jumlah tenaga kerja efektif, jumlah pupuk, jumlah pestisida, pengalaman petani dalam berusaha, jarak rumah petani dengan lahan garapan, dan sistem irigasi berpengaruh nyata terhadap peningkatan produksi padi sawah.

Tabel 3. Hasil Analisis Pengaruh Simultan

\begin{tabular}{lccccc}
\hline \multicolumn{1}{c}{ Model } & $\begin{array}{c}\text { Sum of } \\
\text { Squares }\end{array}$ & Df & $\begin{array}{c}\text { Mean } \\
\text { Square }\end{array}$ & F & \multirow{2}{*}{ Sig. } \\
\hline Regression & $7,483 \mathrm{E} 16$ & 4 & $1,871 \mathrm{E} 16$ & 146,220 & 0,000 \\
Residual & $2,495 \mathrm{E} 16$ & 195 & $1,279 \mathrm{E} 14$ & & \\
\hline Total & $9,978 \mathrm{E} 16$ & 199 & & & \\
\hline
\end{tabular}

Selanjutnya, pengaruh parsial antara faktor produksi utama (FPU), dan faktor produksi pendukung terhadap produksi padi sawah disajikan pada Tabel 4. Berdasarkan hasil analisis faktor produksi utama satu dan faktor pendukung satu yang berpengaruh nyata terhadap produksi, dan yang lainnya tidak berpengaruh pada peluang $(p)=0,05$. Sedangkan apabila dilihat dari $\beta$ faktor produksi pendukung satu bernilai negatif, artinya variabel pupuk, obat-obatan, dan sistem pengelolaan bertambah akan menurunkan produksi padi sawah 
sebesar 23,4\%. Dapat saya asumsikan bahwa hasil penelitian sesuai dengan teori menurut Mubyarto, (1989) yaitu lahan sebagai salah satu faktor produksi yang merupakan pabriknya hasil pertanian yang mempunyai kontribusi yang cukup besar terhadap usahatani. Besar kecilnya produksi dari usahatani antara lain dipengaruhi oleh luas sempitnya lahan yang digunakan. Sedangkan menurut Mosher, (1968) keluarga merupakan salah satu faktor yang mempengaruhi petani dalam pengambilan keputusan untuk pengelolaan usahataninya. Kasih sayang terhadap keluarga dan beban tanggungan yang dimiliki menimbulkan keinginan dan motivasi suami dalam hal ini petani responden untuk dapat menikmati taraf hidup yang lebih baik agar keluarganya hidup lebih bahagia.

Tabel 4. Hasil Analisis Pengaruh Parsial

\begin{tabular}{|c|c|c|c|c|c|}
\hline \multirow{2}{*}{ Model } & \multicolumn{2}{|c|}{ Unstandardized Coefficients } & \multirow{2}{*}{$\begin{array}{c}\begin{array}{c}\text { Standardized } \\
\text { Coefficients }\end{array} \\
\text { Beta }(\beta)\end{array}$} & \multirow{2}{*}{$\mathrm{t}$} & \multirow{2}{*}{ Sig. } \\
\hline & B & Std. Error & & & \\
\hline (Constant) & 6881769,500 & 799834,794 & & 8,604 & 0,000 \\
\hline FPU1 & $2.3,0 \mathrm{E} 7$ & 1518500,028 & 1,058 & 15,608 & 0,000 \\
\hline FPU2 & $-154201,219$ & 819484,106 & $-0,007$ & $-0,188$ & 0,851 \\
\hline FPP1 & $-5230561,143$ & 1500502,572 & $-0,234$ & $-3,486$ & 0,001 \\
\hline FPP2 & 946045,896 & 851990,943 & 0,042 & 1,110 & 0,268 \\
\hline
\end{tabular}

\section{Simpulan}

Secara simultan menunjukkan bahwa secara bersama-sama faktor produksi utama satu dan faktor produksi utama dua yaitu: luas lahan, bibit, penggunaan tenaga kerja, umur, dan pendidikan sedangkan, faktor produksi pendukung satu, dan faktor produksi pendukung dua yaitu: yaitu penggunaan pupuk, obat-obatan, dan sistem pengelolaan yang berpengaruh terhadap produksi padi sawah adalah sangat nyata. Faktor produksi utama satu yakni luas lahan, bibit, penggunaan tenaga kerja, umur, dan pendidikan sedangkan, faktor produksi pendukung satu yaitu penggunaan pupuk, obat-obatan, dan sistem pengelolaan yang berpengaruh nyata terhadap produksi padi sawah. Sedangkan, yang lainnya tidak berpengaruh.

\section{Pustaka}

BPS Kab. TTU 2008. Timor Tengah Utara dalam Angka 2008. Kefamenanu: Badan Pusat Statistik Kabupaten TTU.

Desky, S. 2008. Analisis Faktor-Faktor Yang Mempengaruhi Produksi Padi Di Kabupaten Aceh Tenggara. [Tesis] Medan: Universitas Sumatera Utara.

Ghozali, I. 2004. Model Persamaan Struktural: Konsep dan Aplikasi dengan Program Amos Ver. 5.0. Semarang: Badan Penerbit Universitas Diponegoro.

Mosher, A.T. 1968. Menggerakkan Dan Membangun Pertanian: Sjarat Mutlak Pembangunan Dan Modernisasi. Jakarta: C.V. Yasaguna.

Mubyarto 1989. Pengantar Ekonomi Pertanian. Jakarta: Lembaga Penelitian, Pendidikan dan Penerangan Ekonomi dan Sosial.

Siagian, D. \& Sugiarto 2006. Metode Statistika untuk Bisnis dan Ekonomi. Jakarta: Gramedia Pustaka Utama.

Sugiyono, 2006. Metode Penelitian Kuantitatif, Kualitatif dan $R \&$ D. Bandung: Alfabeta.

Sutrisno, S. \& Ananda, F. 2009. Faktor-faktor yang Mempengaruhi Produksi Padi Studi Kasus di Kecamatan Nogosari, Boyolali, Jawa Tengah. Jurnal WACANA, 12(1): 179-191.

Tenaya, I.M.N. 2006. Bahan Kuliah Statistika Manajerial Program Studi Magister Manajemen Agribisnis.

Triyanto, J. 2006. Analisis Produksi Padi di Jawa Tengah. Tesis. Semarang: Universitas Diponegoro. 